\title{
Epigenetic Treatment of Neurodegenerative Ophthalmic Disorders: An Eye Toward the Future
}

Walter H. Moos, ${ }^{1,2, *}$ Douglas V. Faller, ${ }^{3,4}$ Ioannis P. Glavas, ${ }^{5}$ David N. Harpp, ${ }^{6}$ Michael H. Irwin, ${ }^{7}$ Iphigenia Kanara, ${ }^{8}$ Carl A. Pinkert, ${ }^{9}$ Whitney R. Powers, ${ }^{10,11}$ Kosta Steliou, ${ }^{4,12}$ Demetrios G. Vavvas, ${ }^{13,14, *}$ and Krishna Kodukula ${ }^{2,12,15, *}$

\begin{abstract}
Eye disease is one of the primary medical conditions that requires attention and therapeutic intervention in ageing populations worldwide. Further, the global burden of diabetes and obesity, along with heart disease, all lead to secondary manifestations of ophthalmic distress. Therefore, there is increased interest in developing innovative new approaches that target various mechanisms and sequelae driving conditions that result in adverse vision. The research challenge is even greater given that the terrain of eye diseases is difficult to landscape into a single therapeutic theme. This report addresses the burden of eye disease due to mitochondrial dysfunction, including antioxidant, autophagic, epigenetic, mitophagic, and other cellular processes that modulate the biomedical end result. In this light, we single out lipoic acid as a potent known natural activator of these pathways, along with alternative and potentially more effective conjugates, which together harness the necessary potency, specificity, and biodistribution parameters required for improved therapeutic outcomes.
\end{abstract}

Keywords: antioxidant; carnitine; lipoic acid; macular degeneration; mitochondria; retina

\section{Introduction}

Given the importance of vision and the number of agerelated causes of vision loss (Table 1), including cataracts and macular degeneration, ${ }^{1-3}$ losing the ability to see is one of the greatest fears among the elderly, to some even more than death itself. ${ }^{4}$ The Ancient Greeks regarded vision to be the foremost means by which learning takes place. As early as the latter half of the 6th century Before the Common Era, the philosopher Alcmaeon of Croton ${ }^{5}$ believed that the eyes are connected directly to the brain. ${ }^{6}$ Two centuries later, by dissecting the human eye during autopsies on cadavers carried out in Alexandria, the Greek physician Herophilus of Chalcedon ${ }^{5}$ identified the optic nerves, tracing them directly to the brain. ${ }^{7}$ Today, the subject of the eye and the brain has in many places become

\footnotetext{
${ }^{1}$ Department of Pharmaceutical Chemistry, School of Pharmacy, University of California San Francisco, San Francisco, California.

${ }^{2}$ ShangPharma Innovation, Inc., South San Francisco, California.

${ }^{3}$ Department of Medicine, Boston University School of Medicine, Boston, Massachusetts.

${ }^{4}$ Cancer Research Center, Boston University School of Medicine, Boston, Massachusetts.

${ }^{5}$ Department of Ophthalmology, New York University School of Medicine, New York, New York.

${ }^{6}$ Department of Chemistry, McGill University, Montreal, QC, Canada.

${ }^{7}$ Department of Pathobiology, College of Veterinary Medicine, Auburn University, Auburn, Alabama.

${ }^{8}$ Embassy of Greece in Moscow, Moscow, Russia.

${ }^{9}$ Department of Biological Sciences, College of Arts and Sciences, The University of Alabama, Tuscaloosa, Alabama.

${ }^{10}$ Department of Health Sciences, Boston University, Boston, Massachusetts.

${ }^{11}$ Department of Anatomy, Boston University School of Medicine, Boston, Massachusetts.

${ }^{12}$ PhenoMatriX, Inc., Natick, Massachusetts.

${ }^{13}$ Retina Service, Angiogenesis Laboratory, Massachusetts Eye and Ear Infirmary, Boston, Massachusetts.

${ }^{14}$ Department of Ophthalmology, Harvard Medical School, Boston, Massachusetts.

${ }^{15}$ Bridgewater College, Bridgewater, Virginia.
}

*Address correspondence to: Walter H. Moos, PhD, Department of Pharmaceutical Chemistry, School of Pharmacy, University of California San Francisco, UCSF Box 2280, 600 16th Street, Genentech Hall S512D, San Francisco, CA 94143, E-mail: walter.moos@ucsf.edu or Demetrios G. Vavvas, MD, PhD, Retina Service, Angiogenesis Laboratory, Massachusetts Eye and Ear Infirmary, 243 Charles Street, Boston, MA 02114, E-mail: vavvas@meei.harvard.edu or Krishna Kodukula, PhD, ShangPharma Innovation, Inc., 280 Utah Avenue, South San Francisco, CA 94080, E-mail: kkodukula@gmail.com 
Table 1. Major Causes of Vision Loss Worldwide

\begin{tabular}{|c|c|c|c|}
\hline Causes & Characteristics & $\begin{array}{l}\text { Ranking as a cause } \\
\text { of blindness in } 2010\end{array}$ & $\begin{array}{c}\text { Ranking as a cause } \\
\text { of MSVI in } 2010\end{array}$ \\
\hline Cataracts & Age-related, progressive & 1 & 2 \\
\hline Diabetic retinopathy & Including sequelae & 4 & 5 \\
\hline Glaucoma & All types & 2 & 4 \\
\hline Macular degeneration & Age-related, myopic, macular hole, and other forms & 3 & 3 \\
\hline Refractive errors (uncorrected) & Includes aphakia & 2 & 1 \\
\hline Trachoma & & 5 & 6 \\
\hline
\end{tabular}

Selected sources: Bourne et al., ${ }^{1}$ Tham et al., ${ }^{2}$ Wong et al., ${ }^{3}$ Aires et al..$^{9}$

$\mathrm{MSVI}$, moderate to severe vision impairment.

required reading for students of life sciences. For example, Gregory's book, "Eye and Brain," has been a classic since its first edition in 1966.

The human eye (Fig. 1) is a conveniently accessible, anatomically complex, highly specialized sensory organ with pharmacological properties that are largely organspecific. ${ }^{10,11}$ These properties present unique opportunities to study effects of inflammation and infectious diseases in the eye, with relevance to the brain and central and autonomic nervous systems. ${ }^{10}$ The retina and optic nerve extend from the brain tissue. ${ }^{12,13}$ Similar to the brain, sheltered by the blood-brain barrier as an immune-privileged tissue, the eye is also an immunologically privileged site protected by the bloodretinal barrier. ${ }^{10,11,13-15}$ The retina is one of the highest metabolic oxygen-consuming tissues of the human body, exceeding even that of the brain, ${ }^{4,11,16,17}$ and its photoreceptors have the greatest density of mitochondria of all central nervous system (CNS) neurons. ${ }^{17-19}$ Mitochondria are intracellular organelles that carry multiple copies of a circular, maternally inherited, double-stranded DNA (mtDNA) comprised of $\sim 16,500$ base pairs in mammals. A principal role of mitochondria is to supply adenosine triphosphate (ATP), the bioenergy needed for cellular

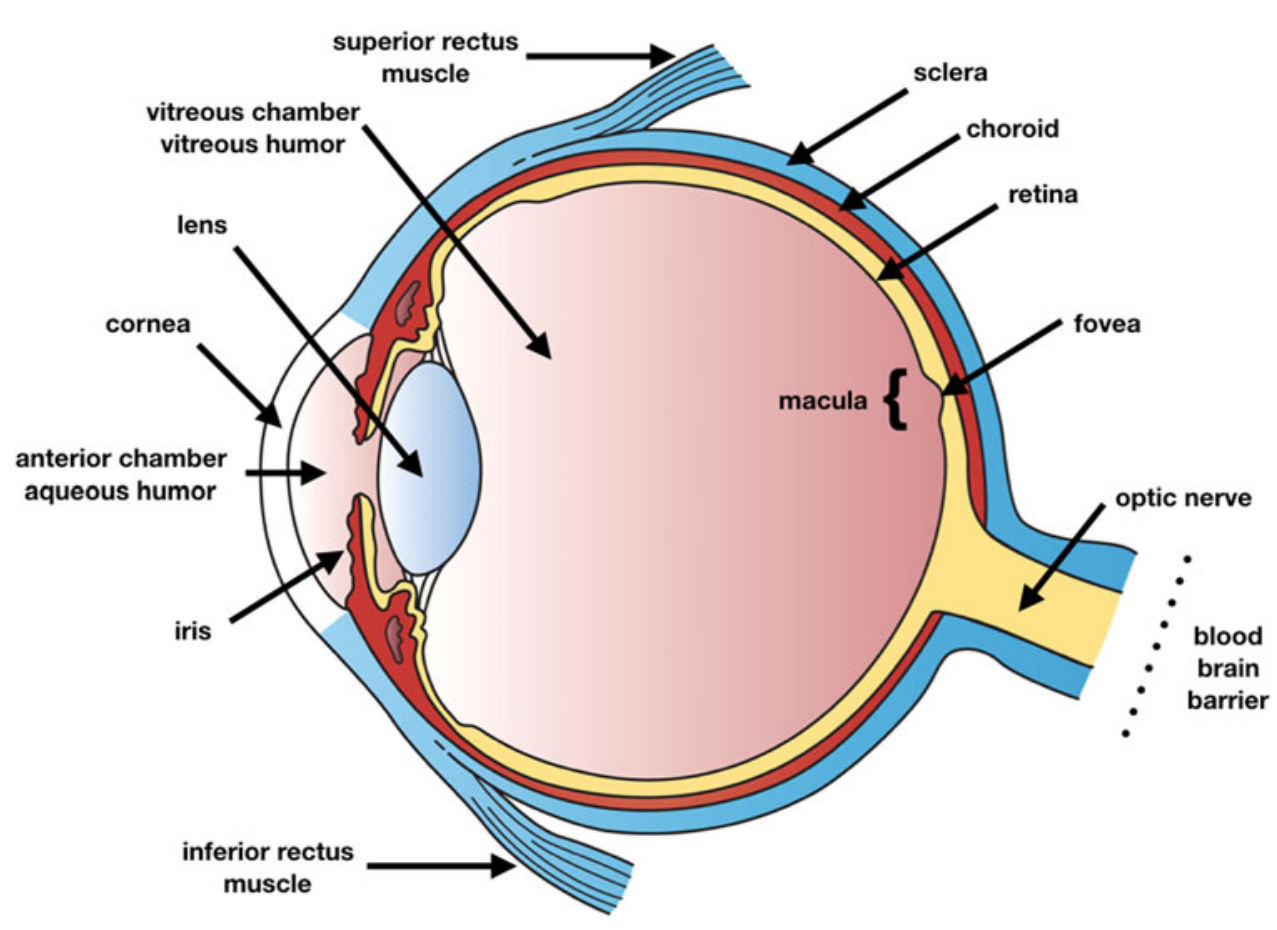

FIG. 1. Basic structure of the human eye. (Adapted from: Artwork by Holly Fischer [CC BY 3.0 (http://creativecommons.org/licenses/by/3.0)], via Wikimedia Commons. Original File URL: https:// upload.wikimedia.org/wikipedia/commons/d/d0/Three_Main_Layers_of_the_Eye.png). 
Table 2. Selected Mitochondrial Diseases and Associated Clinical or Neurological Ophthalmologic Features

\begin{tabular}{ll}
\hline Representative mitochondrial diseases and associated clinical/neurological features & Alternative names and/or causes \\
\hline Chronic progressive external ophthalmoplegia & CPEO \\
$\begin{array}{l}\text { Encephalopathy with enteropathy, neuropathy, and progressive external ophthalmoplegia } \\
\text { Encephalopathy with cardiomyopathy, nephrotic syndrome, deafness, optic }\end{array}$ & MNGIE \\
atrophy, and ataxia & Coenzyme Q10 deficiency \\
Leigh's disease & Subacute necrotizing encephalomyelopathy \\
Leber's hereditary optic neuropathy & LHON \\
Mitochondrial encephalomyopathy, lactic acidosis, and stroke-like episodes & MELAS \\
Mitochondrial DNA deletions or depletion & mtDNA deletions or depletion \\
Myoclonus epilepsy with ragged-red fibers & MERRF \\
Neuropathy, ataxia, and retinitis pigmentosa & NARP; secondary to mtDNA mutation in MT-ATP6 \\
Nuclear DNA point mutations & nDNA point mutations \\
Pearson's/Kearns-Sayre syndrome & Pearson's/KSS \\
Progressive external ophthalmoparesis & PEO \\
\hline
\end{tabular}

Sources: Zhu et al., ${ }^{61}$ Grönlund et al., ${ }^{62}$ McFarland et al., ${ }^{63}$ Yu-Wai-Man and Newman. ${ }^{64}$

maintenance and other essential biochemical processes. ${ }^{20}$ Importantly, when there is a buildup of damaged and/or dysfunctional mitochondria in the optic nerve, the nerve's diminished capacity to produce enough ATP to supply its energy demands can result in severe visual impairment and lead to blindness. ${ }^{21-24}$

Mitochondrial dysfunction is a prominent feature in the disease-progression mechanisms and pathways of a growing list of clinical disorders. ${ }^{25-33}$ Included among these are vision impairments such as cataracts, ${ }^{4,34}$ the most common cause of (preventable) blindness in the world, ${ }^{35,36}$ macular degeneration, ${ }^{4,19,24,37-42}$ diabetic retinopathy, ${ }^{4,19,43-45}$ and optic nerve diseases ${ }^{23,46,47}$ such as glaucoma. ${ }^{4,24,48}$ Glaucoma, an umbrella term for eye conditions that are caused by glaucomatous optic neuropathy, characterized by a progressive retinal ganglion cell loss and visual field damage, ${ }^{47,49,50}$ is the second leading cause of blindness worldwide. ${ }^{9}$ However, the ultimate form of mitochondrial dysfunction is expressed in the primary mitochondrial disorders $^{25,51,52}$ and, with the brain and eye being insatiable consumers of ATP, it is not surprising that neuronal and/or ocular health are inevitable frontline casualties in these diseases. ${ }^{53-55}$

In fact, (neuro-)ophthalmologic assessment ${ }^{56}$ is very much in order when mitochondrial disease is suspected (Table 2), ${ }^{57-59}$ even though significant clinical and genetic heterogeneity is evident in mtDNA mutationdriven disorders. ${ }^{60}$ In one study, 26 of 74 adult and pediatric patients with mitochondrial disease exhibited ophthalmologic abnormalities, ${ }^{61}$ and in another, 46 of 57 children and young adults with genetically verified mitochondrial disease had ophthalmologic findings. ${ }^{62}$ Signs of potential ocular involvement in mitochondrial disease may include hyperpigmentation of the retina, nystagmus, ptosis, ophthalmoplegia, optic atrophy, strabismus, and visual field defects. More extensive examination of the eye is required when the optic nerve itself is involved. Examples of the latter include autosomal dominant optic atrophy-related disorders and Leber's hereditary optic neuropathy. ${ }^{63}$

Although mitochondria in their production of ATP serve as the powerhouses of the cell, ${ }^{20}$ they also function as strategic platforms for intracellular signaling, as modulators of stem cell activity and cell death pathways, and as regulators of innate and adaptive immune responses to viral infections and other biological attacks. ${ }^{32,65-71}$ Indeed, a growing list of studies exposing the pivotal roles mitochondria play in immune-related pathways $^{32,68,70-77}$ is fueling the characterization of mitochondria as the powerhouses of immunity. ${ }^{78}$ Thus, given these essential processes that mitochondria undertake in mitigating cell protection, survival, and function, they are attractive targets of opportunity for diagnostic, prognostic, and therapeutic indications, particularly in diseases of tissues with high energy needs. ${ }^{79}$ Breakthroughs in diagnosing and treating neurological disorders are in great need ${ }^{29-32,80-82}$ and the eye, being an accessible part of the brain, offers a clear window for us to begin to explore.

\section{Ocular Manifestations of Neurological Conditions and Disorders}

For more than two millennia, physicians have looked to the eye as a sentinel indicator of disease. ${ }^{7,83}$ Abnormal avoidance of eye contact is an early risk-marker associated with autism. ${ }^{84-86}$ Several neurodegenerative conditions-Alzheimer's disease (AD), inherited primary 
Table 3. Association of Vision Loss with Other Diseases

\begin{tabular}{|c|c|c|}
\hline Eye disease/indication & Cause/associated condition & Disease progression \\
\hline Diabetic retinopathy ${ }^{45}$ & Diabetes & Progressive degeneration leading to blindness \\
\hline Macular degeneration $^{103}$ & $\begin{array}{l}\text { Aging, complement dysregulation, } \\
\text { oxidation, mitochondrial dysfunction }\end{array}$ & $\begin{array}{l}\text { Progressive degeneration leading to legal } \\
\text { blindness }\end{array}$ \\
\hline Microvascular abnormalities ${ }^{104,105}$ & AD, diabetes, cardiovascular disease & \\
\hline Optic nerve cupping, optic neuropathy ${ }^{104}$ & $\begin{array}{l}\text { Glaucoma, ischemic optic neuropathies. } \\
\text { Compressive optic neuropathies }\end{array}$ & \\
\hline Pupillary abnormalities ${ }^{104}$ & $\begin{array}{l}\text { AD, diabetes, optic nerve and CNS } \\
\text { abnormalities }\end{array}$ & \\
\hline Retinal neurodegeneration (thinning of RNFL) ${ }^{104}$ & $A D, P D$ & \\
\hline $\mathrm{RP}^{64,106}$ & Several hundred genes isolated to day & Progressive blindness \\
\hline Usher syndrome ${ }^{107}$ & Deafness coupled with RP & Progressive degeneration and deterioration \\
\hline
\end{tabular}

$A D$, Alzheimer's disease; PD, Parkinson's disease; RNFL, retinal nerve fiber layer; RP, retinitis pigmentosa.

mitochondrial diseases, Parkinson's disease, and multiple sclerosis among others-have manifestations in the eye. Indeed, ocular symptoms often precede conventional diagnosis of these conditions. ${ }^{13,55,56,87-97}$ In addition to when the eye itself is the target of infection, ocular symptoms are also common to viral diseases that affect the brain and CNS. ${ }^{32,98-102}$ Healthy mitochondrial function is necessary in upholding a competent innate immunity, the body's frontline response against viral infections. ${ }^{32,76,78}$ Although these varied types of neurological and related conditions and disorders can have disparate root causes, they share in common mitochondrial dysfunction in their disease progression pathways. $^{26-32,65}$ Consequently, the eye, not infrequently the first neuronal tissue affected by mitochondrial failure, offers itself as a model for energetic impairment in the CNS with direct implications for degenerative brain diseases ${ }^{53}$ (Table 3 ).

\section{Targeting Mitochondrial Dysfunction in Ocular Diseases}

Many of the familiar features of aging seen in aged animals (including humans) correlate with epigenetic alterations that regulate transcription. ${ }^{108-110}$ Nutritional disequilibrium, epigenetic changes in gene expression, increased genomic instability, an erosion of telomeres, increased cellular senescence, and deregulated nutrient sensing are some of the age-related functional characteristics acting on or with each other that impact other hallmarks such as mitochondrial function and/ or dysfunction and the degradation of an appropriate immune response. ${ }^{66,78,111-115}$

Because mitochondria cannot be produced de novo, ${ }^{116}$ cells rely on the preservation of their healthy mitochondria from which mitochondrial biogenesis (the growth and division of pre-existing mitochondria) can occur. Mitophagy, a sub-form of autophagy, ${ }^{70,72,117-120}$ clears away damaged and/ or dysfunctional mitochondria. ${ }^{25,71,75,111,120-127}$ Not surprisingly, given the irreplaceable nature of the mitochondrion and the indispensable roles mitochondria play in maintaining neuro-(ocular) health, mitoprotection has become an important target of pharmacological intervention-spawning an emerging pharmaceutical interest in developing "mitoprotectors,"23,128-132 and therapeutics for activating antioxidant and/or select mitophagic pathways. $^{72,117,118,122,125,126,133-137}$ This includes dysregulated situations where these pathways and their modulators may be potentially maladaptive, ${ }^{138-141}$ for example, wherein constraining the induction of autophagy or mitophagy is desirable. ${ }^{142}$ However, when autophagy was inhibited in retinal pigment epithelial (RPE) cells subjected to rotenone-induced mitotic catastrophe (MC) in vivo (mice), it caused necrotic cell death-suggesting that cell-controlled autophagy and mitophagy act to prevent the RPE-MC cells from collectively plunging into cell death indiscriminately, and thus help minimize the extent of untoward RPE cell loss. ${ }^{143}$

\section{$\alpha$-Lipoic Acid and L-Carnitine}

(R)-5-(1,2-dithiolan-3-yl)pentanoic acid, commonly known as $\alpha$-lipoic acid (ALA, Fig. 2) and its reduced form (R)-6,8-bis(sulfanyl)octanoic acid, commonly referred to as dihydrolipoic acid (DHLA, Fig. 2) are enzymatically synthesized in mitochondria from octanoic acid. ${ }^{144}$ ALA and DHLA are naturally occurring cofactors for vital metabolic multi-enzyme complexes, including pyruvate dehydrogenase and glycine decarboxylase. ${ }^{144-146}$ They possess powerful antioxidative effects ${ }^{28,145,147,148}$ and anti-inflammatory activity, ${ }^{149}$ instigate signal transduction modulatory pathways, ${ }^{32,150}$ and are well known to stimulate the expression of nerve growth factor ${ }^{148,151,152}$ and enhance conduction velocity of motor nerves. ${ }^{148,153}$ 
<smiles>O=C(O)CCCCC1CCSS1</smiles>

(ALA)<smiles>O=C(O)CCCCC(S)CCS</smiles>

(DHLA)<smiles>COC(=O)CC(CN(C)C)OC(=O)CCCCC1CCSS1</smiles>

Lipoyl-L-carnitine methyl ester iodide (PMX500FI)<smiles></smiles>

(EV06)<smiles>CCCCC1CCSS1</smiles>

MitoL<smiles>O=C(CCCCC1CCSS1)OCCCCP</smiles>

revMitoLipAc<smiles>COc1cc2ccc(=O)oc2cc1OC(=O)CCCCC1CCSS1</smiles>

Scopoletin lipoate (UPEI-400)<smiles>O=C(CCCCC1CCSS1)NCCCNc1c2c(nc3cc(Cl)ccc13)CCCC2</smiles>

Lipocrine<smiles>CCCCCCNC(=O)C(C)c1ccc(CC(C)C)cc1</smiles>

Lipoamide-ibuprofen conjugates $(n=2 ; 4 ; 6)$<smiles>CC(c1cccc(OCCCNC(=O)CCCCC2CCSS2)c1)N(C)C</smiles>

Lipoamide-rivastigmine conjugate

FIG. 2. ALA-conjugates: PMX500F ${ }^{28,154,155} ; \mathrm{EV}^{156}{ }^{156}$; Lipoamide-ibuprofen conjugates $(n=2 ; 4 ; 6)^{157,158}$; Lipoamide-rivastigmine conjugate, Lipocrine ${ }^{159}$; MiotL, revMitoLipAc ${ }^{160}$; Scopoletin lipoate. ${ }^{161}$ ALA, $\alpha$-lipoic acid.

Additionally, ALA has significant histone deacetylase (HDAC) inhibitory activity. ${ }^{31,145}$ It is a potent activator of the nuclear factor erythroid 2-related factor 2 (Nrf2)/antioxidant response element (ARE) signaling pathway, ${ }^{28-32,162,163}$ which plays a central role in cellular defense against oxidative stress and the subsequent upregulation of ARE-dependent cytoprotective genes, including the heme oxygenase- 1 , catalase, and superoxide dismutase genes, without exhibiting cytotoxicity. ${ }^{164,165}$ $\mathrm{Nrf2}$ is essential for supporting and maintaining normal mitochondrial function and structural integrity, particularly under conditions of cellular/neuronal stress inherent in neurodegenerative disorders. ${ }^{29}$ Oxidative stress is one of the main factors contributing to the pathogenesis of age-related macular degeneration (AMD), ${ }^{39,40,166-169}$ the most common cause of blindness in the elderly ${ }^{3,15,167,170,171}$ and the thirdleading cause of blindness worldwide ${ }^{3}$ (Table 4).
Nrf2-mediated activity has been shown to decrease in aged rodents compared to younger pups, and in humans, in macrophages from older smokers in comparison with older nonsmokers, and in the affected brain regions of $\mathrm{AD}$ patients. ${ }^{166}$

Although ALA reaps much attention in clinical therapy against a host of diseases susceptible to reactive oxygen species, including radiation exposure scenarios and heavy metal toxicity, ${ }^{28,175}$ its poor pharmacokinetic (PK) properties ${ }^{43,176-179}$ are a barrier to achieving sustainable therapeutic concentrations in vivo. ${ }^{163,177,180,181}$ This PK deficit limits the range of ALA's potential clinical indications. Nonetheless, ALA is an effective treatment option for diabetic neuropathy ${ }^{43,182}$ and possibly helpful in diabetic retinopathy, ${ }^{183}$ as outlined below.

In a clinical study evaluating oxidative stress, preretinopathic diabetic subjects who received oral treatment with ALA in combination with other antioxidants showed a 


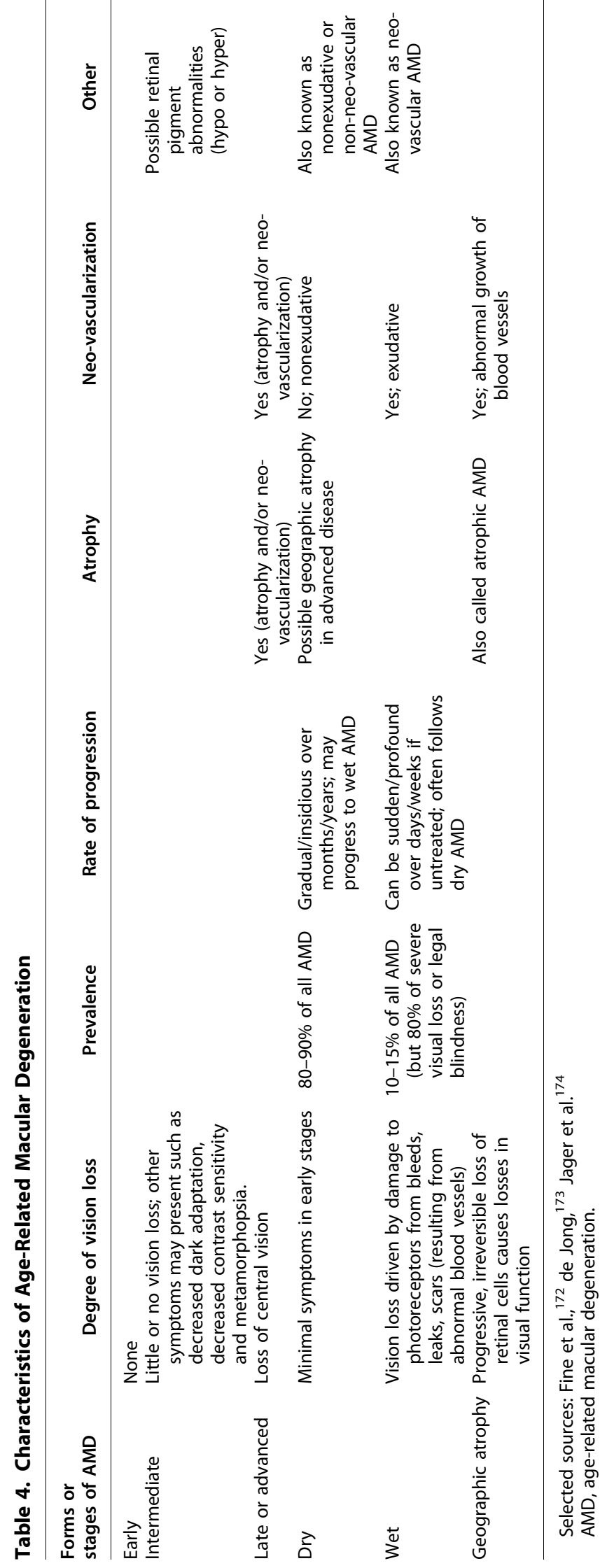

significant benefit in retinal elements-presumably due to a protective antioxidant effect on retinal cells (as determined by electroretinogram analysis). ${ }^{184}$ A protective antioxidant effect was also noted in a separate randomly assigned clinical trial involving 100 patients with dry AMD (50 patients given an oral administration of $0.2 \mathrm{~g}$ of ALA capsules daily for 3 months, and a control group of 50 patients receiving an oral administration of $1 \mathrm{~g}$ of vitamin C daily). Using the Chinese-Version Low Vision Quality of Life Questionnaire to assess vision-related quality of life, the ALA-treated group scored higher vs. the control group. ${ }^{185}$ In a study using a rat model of optic nerve crush injury, ALA administered intravenously $(63 \mathrm{mg} / \mathrm{kg})$ 1 day before or 1 day after the ONC injury was shown to have neuroprotective effects on retinal ganglion cells and a stronger prophylactic effect in the retina of the ONCrats receiving ALA the day before the ONC injury. ${ }^{186}$ In a preliminary study with a higher species animal model (diabetic dogs) given ALA ( $2 \mathrm{mg} / \mathrm{kg}$ ) orally, with ALA possibly acting as an antioxidant and/or as an aldose reductase inhibitor, the onset of glucose-sorbitol-induced cataracts was delayed, suggesting that the use of ALA should be studied for treating aldose-reductase-associated diabetic retinopathy in humans. ${ }^{187}$

However, to more fully take advantage of ALA's clinical potential as a drug candidate (particularly in ocular indications), its PK drawbacks must be resolved. With this in mind, mitochondria-targeting ALA-conjugated esters were conceived and synthesized. Chemical structures representing some of the conjugates that have been shown to have improved bioavailability and activity in vivo are shown in Figure 2. ${ }^{27,28,154-161,188-190}$

EV06 and PMX500FI (Fig. 2) are covalently linked esters of natural substrates (EV06: ALA and choline ${ }^{156}$; PMX500FI: ALA and L-carnitine ${ }^{28,154,155}$ ) that localize to and are operated on in mitochondria. A detailed and elegant study highlighting the anticancer properties of ALA (acting as a modulator of signal transduction and gene expression) inhibiting HDAC activity in human tumor cells was reported by van de Mark et al. ${ }^{145}$ In this study, choline was used as the vehicle (control), as it apparently has no noteworthy activity of its own in the assays used. However, choline is an essential nutrient and methyl donor required for epigenetic regulation, ${ }^{191}$ and choline acetyltransferase (an enzyme that catalyzes the biosynthesis of the neurotransmitter, acetylcholine) is well-represented in ocular tissues of the human eye $^{192}$ and in cholinergic cells of the brain and CNS. ${ }^{193}$

L-Carnitine [L-(3R)-3-hydroxy-4-(trimethylammonio)butanoate], a natural compound primarily obtained from 
meat-containing foods in the diet and/or endogenously synthesized in the body, ${ }^{194}$ is a necessary nutrient of metabolic oxidation. ${ }^{195}$ It is required in the transport of medium-chain and long-chain fatty acids (acyl groups) between cell organelles and into the mitochondrial matrix where $\beta$-oxidation occurs, and in the removal of intermediate toxic products out of the mitochondria for excretion in urine. ${ }^{154,194,196,197}$ In combination with carnitine acyltransferases (a family of enzymes that catalyze the reversible transfer of acyl groups between coenzyme A [CoA] and L-carnitine), acyl-carnitine esters are converted into acyl-CoA esters, the active acyl substrate operated on by the mitochondrial enzymes in $\beta$-oxidation; in the export of excess acetyl groups from the mitochondria; and in acetylation reactions that regulate gene transcription and enzyme activity. ${ }^{194}$ L-carnitine has also been shown to confer protection in the prevention of radiation-induced brain and retinal damages. ${ }^{198,199}$

\section{Nrf2, and Epigenetic Attributes of ALA, L-Carnitine, and Their Conjugated Esters}

Retinal diseases and/or damages leading to a substantial loss of retinal neurons can result in visual impairment that may be permanent. The adult mammalian retina has little capacity for regeneration, ${ }^{200,201}$ and as noted previously, unmitigated oxidative stresses in ocular tissues can cause irreversible harm to the eye. The Nrf2-Kelchlike $\mathrm{ECH}$-associated protein 1 (Keap1) assembly is one of the main cellular defense systems against oxidative stresses. ${ }^{110,169,202} \mathrm{Nrf2}$ is a key nuclear transcriptional inducer. It couples with ARE in the DNA promoter and synchronizes the transcription of a large number of antioxidant genes, including glutathione-S transferase, glutathione reductase, and thioredoxin reductase. ${ }^{110}$ Notably, the Nrf2/ARE/Keap1 signaling pathway regulates antiinflammatory gene expression and inhibits the progression of inflammation. ${ }^{203}$ Relevant to this discussion, ALA and L-carnitine, separately and/or as a conjugate ester (PMX500FI), are HDAC inhibitors that independently may act to prolong epigenetic gene expression. ${ }^{31}$

$\mathrm{Nrf} 2$ production ( $\mathrm{Nfe} 2 \mathrm{l} 2$ gene expression) has been demonstrated (in animals) to decline progressively with age, ${ }^{141,166}$ and this may in part account for the retinopathies, ${ }^{45}$ including macular degeneration, presenting as age-related diseases of the eye. ${ }^{204-206}$ An imbalance in oxidative stress and antioxidant defense mechanisms contributes to the pathogenesis of both inherited and acquired corneal pathologies ${ }^{23,24}$ and to the development of ischemic retinopathies such as diabetic retinopathy and retinopathy of prematurity. ${ }^{207} \mathrm{~A}$ study designed to model retinopathies in mice showed that Nrf2 activation reduced the vision-threatening features of oxygen-induced retinopathy, namely vasoobliteration, neovascularization, and vascular leakage, with potential therapeutic utility. ${ }^{207}$

Interestingly, activation of the Nrf2 cell defense pathway can also be influenced by diet. ${ }^{208-214}$ Deregulated nutrient sensing is one of the hallmarks of aging ${ }^{112,114}$ and numerous studies link elevated levels of oxidative stress and inflammatory changes in various tissues and organs to a dysbiotic shift in the gut microbiota. ${ }^{30,215}$ Kugadas et al. ${ }^{216}$ suggest that pathogenic bacteria in the gut may affect ocular disease susceptibility, and provide experimental evidence for the existence of a gut-eye axis of immune regulation. A study by Rowan et al. ${ }^{217}$ discovered that metabolites and microbiota, acting together within a gut-retina axis, appear to protect against diet- and age-induced AMD features-implying that a simple dietary intervention may have complementary use in the treatment of patients with AMD. ${ }^{218,219}$ Indeed, metabolomics is an emerging and promising laboratory testing technique for identifying blood profiles associated with AMD across all its stages and severity. ${ }^{220}$ Microbiome research in general is an aggressive field of study and although the gut microbiome has captured most of the attention, ${ }^{215}$ the microbiota on the surface of the human eye (ocular microbiome) is drawing increasing interest as a unique and immunoprotective commensal ecosystem. ${ }^{32,216,221-224}$

\section{Concluding Remarks}

As should be clear at this point, eye disease is a primary medical condition that often requires immediate attention and therapeutic intervention in ageing populations worldwide, not to mention pediatric and young adult patients. Exacerbating the problem is the increasing global burden of diabetes and obesity, along with heart disease, which all lead to significant secondary and tertiary manifestations of ophthalmic distress. Even less serious challenges such as managing dysfunctional tear syndrome continue to frustrate greatly both patients and eye care professionals. ${ }^{25,226}$ Therefore, increased interest is manifold in developing innovative new approaches that target various mechanisms and sequelae driving conditions that result in adverse vision. The research and development challenges are even greater given that the varied and extensive terrain of eye diseases is difficult to landscape into a single or even two or three therapeutic themes, although some would say that all roads may ultimately lead to mitochondria. 
Thus, in this report, we have attempted to address the burden of eye disease due to mitochondrial dysfunction, including antioxidant, autophagic, epigenetic, mitophagic, and other essential cellular processes that modulate the biomedical end result. In such a light, it is appropriate to single out lipoic acid as a potent known natural activator of these pathways, along with alternative and potentially more effective carnitine conjugates, which together we anticipate could harness the necessary and complete profile of potency, specificity, and biodistribution parameters that are required for improved therapeutic outcomes.

In particular, Nrf2 is an important endogenous protective factor against oxidative stress and essential for supporting and maintaining normal mitochondrial function, especially in neuroretinal and other high energy-demanding tissues. The clinical development of drugs that modulate Nrf2 expression is vigorously being researched as a neuroprotective strategy for treating conditions of oxidative stress, including age-related cataracts and AMD. ${ }^{24,110,169,202,227-233}$

Eye disease is reaching epidemic proportions worldwide. $^{234}$ As yet one more example, it is estimated that the incidence of glaucoma will exceed 100 million cases by $2040,{ }^{235-238}$ and most of the people affected will reside in Asia and Africa. ${ }^{2}$ These healthcare juggernauts are due to primary causes as well as secondary manifestations resulting from metabolic distress in the eye, brain, and elsewhere in the body where energy demanding cell types are resident-again, think mitochondria. ${ }^{239}$ Ageing populations add to the burden. The revival of interest in developing novel eye disease therapies ${ }^{237-241}$ is consequently no surprise. We hope that our review convinces even more researchers to join the search for the next generation of safe and effective ophthalmic medicines.

\section{Acknowledgments}

We gratefully acknowledge the generous financial support from the MitoCure Foundation and thank Dr. Robert J. Zamboni (McGill University) for his invaluable advice and helpful discussions in the preparation of this article.

\section{Authors' Contributions}

All authors contributed to the writing of this article and agreed to its final content.

\section{Author Disclosure Statement}

K.S. owns shares in PhenoMatriX, Inc. K.K. and W.H.M. consult with and/or serve on the boards of various biotechnology and pharmaceutical companies from time to time, where they may receive compensation and/or stock options, and they receive compensation from ShangPharma Innovation, Inc., a healthcare venture capital firm.

\section{References}

1. Bourne RR, Stevens GA, White RA, et al. Causes of vision loss worldwide, 1990-2010: a systematic analysis. Lancet Glob Health. 2013;1:e339e349.

2. Tham Y-C, Li X, Wong TY, et al. Global prevalence of glaucoma and projections of glaucoma burden through 2040. A systematic review and meta-analysis. Ophthalmology. 2014;121:2081-2090.

3. Wong WL, Su X, Li X, et al. Global prevalence of age-related macular degeneration and disease burden projection for 2020 and 2040: a systematic review and meta-analysis. Lancet Glob Health. 2014;2:e106e116.

4. Babizhayev MA. Drug design of mitochondria-targeted antioxidants, action, metabolism and perspectives for ophthalmic therapeutics: $\mathrm{N}$-acetylcarnosine codrug treatment platform. Int J Ophthalmol Eye Res. 2017:5:287-307.

5. Bowder D (ed.). Who Was Who in the Greek World: 776 BC-30 BC. Cornell University Press: Ithaca, NY; p. 240; 1982.

6. Bertman S. The Genesis of Science: The Story of Greek Imagination. Prometheus Books: Amherst, NY; p. 293; 2010.

7. Standring S. A brief history of topographical anatomy. J Anat. 2016;229: 32-62.

8. Gregory RL. Eye and Brain: The Psychology of Seeing, 5th ed. Princeton University Press: Princeton, NJ; p. 288; 2015.

9. Aires ID, Ambrósio AF, Santiago AR. Modeling human glaucoma: lessons from the in vitro models. Ophthalmic Res. 2017;57:77-86.

10. Moroi SE, Lichter PR. Ocular Pharmacology. In: Goodman and Gilman's The Pharmacological Basis of Therapeutics, 10th ed. Hardman J, Limbrd LE, (eds.) McGraw-Hill: New York; pp. 1821-1845; 2001.

11. Awwad S, Ahmed AHAM, Sharma G, et al. Principles of pharmacology in the eye. Br J Pharmacol. 2017;174:4205-4223.

12. Vladan B, Panfoli I. Melatonin and abeta, macular degeneration and Alzheimer's Disease: same disease, different outcomes? MEHDI Ophthalmol J. 2012;1:24-32.

13. London A, Benhar I, Schwartz M. The retina as a window to the brain-from eye research to CNS disorders. Nat Rev Neurol. 2013; 9:44-53.

14. Horai $R$, Zárate-Bladés $C R$, Dillenburg-Pilla $P$, et al. Microbiota-dependent activation of an autoreactive $T$ cell receptor provokes autoimmunity in an immunologically privileged site. Immunity. 2015;43:343-353.

15. Shafaie S, Hutter V, Cook MT, et al. In vitro cell models for ophthalmic drug development applications. BioRes Open Access. 2016;5:94-108.

16. Anderson B, Saltzman HA. Retinal oxygen utilization measured by hyperbaric blackout. Arch Ophthalmol. 1964;72:792-795.

17. Wong-Riley MT. Energy metabolism of the visual system. Eye Brain. 2010; 2:99-116.

18. Hoang QV, Linsenmeier RA, Chung CK, et al. Photoreceptor inner segments in monkey and human retina: mitochondrial density, optics, and regional variation. Vis Neurosci. 2002;19:395-407.

19. Fu Z, Gong Y, Löfqvist $C$, et al. Review: adiponectin in retinopathy. BBA Mol Basis Dis. 2016;1862:1392-1400.

20. McBride HM, Neuspiel M, Wasiak S. Mitochondria: more than just a powerhouse. Curr Biol. 2006;16:R551-R560.

21. Sadun A. Acquired mitochondrial impairment as a cause of optic nerve disease. Trans Am Ophthalmol Soc. 1998;96:881-923.

22. Chhetri J, Gueven N. Targeting mitochondrial function to protect against vision loss. Expert Opin Ther Targets. 2016;20:721-736.

23. Gueven N, Nadikudi M, Daniel A, et al. Targeting mitochondrial function to treat optic neuropathy. Mitochondrion. 2017;36:7-14.

24. Vallabh NA, Romano V, Willoughby CE. Mitochondrial dysfunction and oxidative stress in corneal disease. Mitochondrion. 2017;36: 103-113.

25. Wallace DC. A mitochondrial bioenergetic etiology of disease. J Clin Invest. 2013:123:1405-1412. 
26. Moos WH, Dykens JA. Mitochondrial drugs come of age. Drug Dev Res. 2015;76:57-60.

27. Parameshwaran K, Irwin MH, Steliou K, et al. Antioxidant-mediated reversal of oxidative damage in mouse modeling of complex I inhibition. Drug Dev Res. 2015;76:72-81.

28. Steliou K, Faller DV, Pinkert CA, et al. Bioprotective carnitinoids: lipoic acid, butyrate, and mitochondria-targeting to treat radiation injury. Drug Dev Res. 2015;76:167-175.

29. Irwin $\mathrm{MH}$, Moos $\mathrm{WH}$, Faller DV, et al. Epigenetic treatment of neurodegenerative disorders: Alzheimer and Parkinson diseases. Drug Dev Res. 2016;77:109-123.

30. Moos WH, Faller DV, Harpp DN, et al. Microbiota and neurological disorders: a gut feeling. BioRes Open Access. 2016;5:137-145.

31. Moos WH, Maneta $E$, Pinkert CA, et al. Epigenetic treatment of neuropsychiatric disorders: autism and schizophrenia. Drug Dev Res. 2016;77: 53-72.

32. Moos WH, Pinkert CA, Irwin MH, et al. Epigenetic treatment of persistent viral infections. Drug Dev Res. 2017;78:24-36.

33. Murphy E, Ardehali H, Balaban RS, et al. Mitochondrial function, biology, and role in disease: a scientific statement from the American Heart Association. Circ Res. 2016;118:1960-1991.

34. Fragaki K, Chaussenot A, Benoist J-F, et al. Coenzyme Q10 defects may be associated with a deficiency of Q10-independent mitochondrial respiratory chain complexes. Biol Res. 2016;49:4.

35. Makley LN, McMenimen KA, DeVree BT, et al. Pharmacological chaperone for $\alpha$-crystallin partially restores transparency in cataract models. Science. 2015;350:674-677.

36. Quinlan RA. A new dawn for cataracts. Science. 2015;350:636-637.

37. Jarrett SG, Lin H, Godley BF, et al. Mitochondrial DNA damage and its potential role in retinal degeneration. Prog Retin Eye Res. 2008;27:596607.

38. Lin $\mathrm{H}, \mathrm{Xu} \mathrm{H}$, Liang FQ, et al. Mitochondrial DNA damage and repair in RPE associated with aging and age-related macular degeneration. Invest Ophthalmol Vis Sci. 2011;52:3521-3529.

39. Murakami Y, Notomi S, Hisatomi T, et al. Photoreceptor cell death and rescue in retinal detachment and degenerations. Prog Retin Eye Res. 2013;37:114-140.

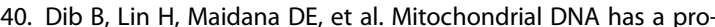
inflammatory role in AMD. BBA Mol Cell Res. 2015;1853:2897-2906.

41. Cousins SW. Role of mitochondrial dysfunction in dry age-related macular degeneration. Retina Today. 2015;May/June:83-85.

42. Tian B, Maidana DE, Dib B, et al. miR-17-3p Exacerbates oxidative damage in human retinal pigment epithelial cells. PLoS One. 2016;11: e0160887

43. Papanas $\mathrm{N}$, Ziegler D. Efficacy of $\alpha$-lipoic acid in diabetic neuropathy. Expert Opin Pharmacother. 2014;15:2721-2731.

44. Kowluru RA, Kowluru AK, Mishra M, et al. Oxidative stress and epigenetic modifications in the pathogenesis of diabetic retinopathy. Prog Retin Eye Res. 2015:48:40-61.

45. Kowluru RA, Mishra M. Epigenetic regulation of redox signaling in diabetic retinopathy: Role of Nrf2. Free Radic Biol Med. 2017;103:155-164.

46. Carelli V, Ross-Cisneros FN, Sadun AA. Mitochondrial dysfunction as a cause of optic neuropathies. Prog in Retin Eye Res. 2004;23:53-89.

47. Sanchez MIGL, Crowston JG, Mackey DA, et al. Emerging mitochondrial therapeutic targets in optic neuropathies. Pharmacol Therapeut. 2016; 165:132-152.

48. Pelletier AL, Rojas-Roldan L. Coffin J. Vision loss in older adults. Am Fam Physician. 2016;94:219-226.

49. Ritch R. Natural compounds: evidence for a protective role in eye disease. Can J Ophthalmol. 2007;42:425-438.

50. Song W, Huang $P$, Zhang C. Neuroprotective therapies for glaucoma. Drug Des Devel Ther. 2015;9:1469-1479.

51. Pavlakis SG, Hirano M. Mitochondrial diseases: a clinical and molecular history. Pediatr Neurol. 2016;63:3-5.

52. Chen Q, Lesnefsky EJ. A new strategy to treat mitochondrial disease without improvement of mitochondrial function? eBioMedicine. 2017; 18:19-20.

53. Van Bergen NJ, Chakrabarti R, O'Neill EC, et al. Mitochondrial disorders and the eye. Eye Brain. 2011;3:29-47.

54. Chaturvedi RK, Beal MF. Mitochondrial diseases of the brain. Free Radic Biol Med. 2013;63:1-29.
55. Kamel K, Farrell M, O'Brien C. Mitochondrial dysfunction in ocular disease: focus on glaucoma. Mitochondrion. 2017;35:44-53.

56. Fraser JA, Biousse V, Newman NJ. The neuro-ophthalmology of mitochondrial disease. Surv Ophthalmol. 2010;55:299-334.

57. Schapira AH. Mitochondrial disease. Lancet. 2006;368:70-82.

58. Mitochondrial Medicine Society's Committee on Diagnosis, Haas $\mathrm{RH}$ Parikh S, et al. The in-depth evaluation of suspected mitochondrial disease. Mol Genet Metab. 2008;94:16-37.

59. Dimmock DP, Lawlor MW. Presentation and diagnostic evaluation of mitochondrial disease. Pediatr Clin. 2017;64:161-171.

60. DiMauro S, Schon EA. Mitochondrial respiratory-chain diseases. N Engl J Med. 2003;348:2656-2668.

61. Zhu C-C, Traboulsi El, Parikh S. Ophthalmological findings in 74 patients with mitochondrial disease. Ophthalmic Genet. 2017;38:67-69.

62. Grönlund MA, Honarvar AKS, Andersson S, et al. Ophthalmological findings in children and young adults with genetically verified mitochondrial disease. Br J Ophthalmol. 2010;94:121-127.

63. McFarland R, Taylor RW, Turnbull DM. A neurological perspective on mitochondrial disease. Lancet Neurol. 2010;9:829-840.

64. Yu-Wai-Man P, Newman NJ. Inherited eye-related disorders due to mitochondrial dysfunction. Hum Mol Genet. 2017;26:R12-R20.

65. Cherry C, Thompson B, Saptarshi N, et al. A "mitochondria" odyssey. Trends Mol Med. 2016;22:391-403.

66. Sun N, Youle RJ, Finkel T. The mitochondrial basis of aging. Mol Cell. 2016;61:654-666.

67. Thomas S, Gale M Jr. Mitochondria and antiviral immunity. In: Mitochondria and Cell Death. Hockenbery DM, (ed.) Springer: New York; Chapter 10, pp. 187-212 (doi:10.1007/978-1-4939-3612-0_10).

68. Hsu P, Shi Y. Regulation of autophagy by mitochondrial phospholipids in health and diseases. BBA Mol Cell Biol Lipid. 2017;1862:114-129.

69. Li PA, Hou X, Hao S. Mitochondrial biogenesis in neurodegeneration. J Neurosci Res. 2017;95:2025-2029.

70. Molino D, Zemirli N, Codogno P, et al. The journey of the autophagosome through mammalian cell organelles and membranes. J Mol Biol. 2017;429:497-514.

71. Ueta CB, Gomes KS, Ribeiro MA, et al. Disruption of mitochondrial quality control in peripheral artery disease: new therapeutic opportunities. Pharmacol Res. 2017;115:96-106.

72. Boya P, Esteban-Martínez L, Serrano-Puebla A, et al. Autophagy in the eye: development, degeneration, and aging. Prog Retin Eye Res. 2016; 55:206-245.

73. Holmbeck MA, Shadel GS. Mitochondria provide a 'complex' solution to a bacterial problem. Nat Immunol. 2016;17:1009-1010.

74. Weber-Gerlach $M$, Weber F. Standing on three legs: antiviral activities of RIG-I against influenza viruses. Curr Opin Immunol. 2016;42: 71-75.

75. Galluzzi L, Pedro JMB-S, Levine B, et al. Pharmacological modulation of autophagy: therapeutic potential and persisting obstacles. Nat Rev Drug Discov. 2017;16:487-511.

76. Monlun $M$, Hyernard $C$, Blanco $P$, et al. Mitochondria as molecular platforms integrating multiple innate immune signalings. J Mol Biol. 2017:429:1-13.

77. West AP, Shadel GS. Mitochondrial DNA in innate immune responses and inflammatory pathology. Nat Rev Immunol. 2017;17:363-375.

78. Mills EL, Kelly B, O'Neill LAJ. Mitochondria are the powerhouses of immunity. Nat Immunol. 2017;18:488-498.

79. Wang W, Karamanlidis G, Tian R. Novel targets for mitochondrial medicine. Sci Transl Med. 2016;8:326rv3.

80. Kinch MS. An analysis of FDA-approved drugs for neurological disorders. Drug Discov Today. 2015;20:1040-1043.

81. Griesenauer RH, Kinch MS. 2016 in review: FDA approvals of new molecular entities. Drug Discov Today. 2017;22:1593-1597.

82. Hempel CM, Werley CA, Dempsey GT, et al. Targeting neuronal function for CNS drug discovery. Drug Discov Today. 2017;23:17-25.

83. Hippocrates. 460-380 BCE. On ancient medicine. In: The Works of Hippocrates. Dunkas N, Sioras N. (eds.) Diachronic Publications: Athens, Hellas; pp. 81-170; 1998.

84. Shivanvitha E, Kamarapu P. Autism-neurodevelopment disorder. Autism Open Access. 2016;6:6.

85. Sztainberg Y, Zoghbi HY. Lessons learned from studying syndromic autism spectrum disorders. Nat Neurosci. 2016;19:1408-1418. 
86. van Karnebeek CDM, Bowden K, Berry-Kravis E. Treatment of neurogenetic developmental conditions: from 2016 into the future. Pediatr Neurol. 2016;65:1-13.

87. Miller NR, Newman NJ. The eye in neurological disease. Lancet. 2004; 364:2045-2054.

88. Ghate D, Vedanarayanan V, Kamour A, et al. Optic nerve morphology as marker for disease severity in cerebral palsy of perinatal origin. $J$ Neurol Sci. 2016;368:25-31.

89. Gupta VK, Gupta VB. Using technology, bioinformatics and health informatics approaches to improve learning Experiences in optometry education, research and practice. Healthcare. 2016;4:86.

90. Javaid FZ, Brenton J, Guo L, et al. Visual and ocular manifestations of Alzheimer's disease and their use as biomarkers for diagnosis and progression. Front Neurol. 2016;7:55

91. Liu L, MacKenzie KR, Putluri N, et al. The glia-neuron lactate shuttle and elevated ROS promote lipid synthesis in neurons and lipid droplet accumulation in glia via APOE/D. Cell Metab. 2017;26: 719-737.

92. More SS, Beach JM, Vince R. Early detection of amyloidopathy in Alzheimer's mice by hyperspectral endoscopy. Invest Ophthalmol Vis Sci. 2016;57:3231-3238.

93. Cordeiro MF, Normando EM, Cardoso J, et al. Real-time imaging of single neuronal cell apoptosis in patients with glaucoma. Brain. 2017;140: 1757-1767.

94. DeBuc CD, Somfai GM, Koller A. Retinal microvascular network alterations: potential biomarkers of cerebrovascular and neural diseases. Am J Physiol Heart Circ Physiol. 2017;312:H201-H212.

95. Koronyo Y, Biggs D, Barron E, et al. Retinal amyloid pathology and proofof-concept imaging trial in Alzheimer's disease. JCI Insight. 2017;2: e93621.

96. Petzold A, Balcer $L J$, Calabresi PA, et al. Retinal layer segmentation in multiple sclerosis: a systematic review and meta-analysis. Lancet Neurol. 2017;16:797-812.

97. Stefánsson $E$, Olafsdottir $O B$, Einarsdottir $A B$, et al. Retinal oximetry discovers novel biomarkers in retinal and brain diseases. Invest Ophthalmol Vis Sci. 2017;58:BIO227-BIO233.

98. Fardeau C, Champion E, Massamba N, et al. Uveitic macular edema. Nat Eye. 2016:30:1277-1292

99. Mammas IN, Greenough A, Theodoridou M, et al. Current views and advances on paediatric virology: an update for paediatric trainees (Review). Exp Ther Med. 2016;11: 6-14.

100. Song J, Huang YF, Zhang WJ, et al. Ocular diseases: immunological and molecular mechanisms. Int J Ophthalmol. 2016:9:780-788.

101. Prakalapakorn SG, Meaney-Delman D, Honein MA, et al. The eyes as a window to improved understanding of the prenatal effects of Zika virus infection. J AAPOS. 2017;259-261.

102. Zhao Z, Yang M, Azar SR, et al. Viral retinopathy in experimental models of Zika infection. Invest Ophthalmol Vis Sci. 2017;58:4075-4085.

103. McGuinness MB, Karahalios A, Finger RP, et al. Age-related macular degeneration and mortality: a systematic review and meta-analysis. Ophthalmic Epidemiol. 2017;24:141-152.

104. Mazzarella J, Cole J. All eyes on neurodegenerative disease. Rev Optom. 2016;153(2):42-52.

105. McClintic BR, McClintic Jl, Bisognano JD, et al. The relationship between retinal microvascular abnormalities and coronary heart disease: a review. Am J Med. 2010;123:374.e1-374.e7.

106. Dykens JA, Carroll AK, Wiley S, et al. Photoreceptor preservation in the S334ter model of retinitis pigmentosa by a novel estradiol analog. Biochem Pharmacol. 2004;68:1971-1984.

107. Sengillo JD, Justus S, Tsai Y-T, et al. Gene and cell-based therapies for inherited retinal disorders: an update. Am J Med Genet Part C Semin Med Genet. 2016;172C:349-366.

108. Garatachea N, Pareja-Galeano H, Sanchis-Gomar F, et al. Exercise attenuates the major hallmarks of aging. Rejuvenation Res. 2015;18: 57-89.

109. da Costa JP, Vitorino R, Silva GM, et al. A synopsis on aging-theories, mechanisms and future prospects. Ageing Res Rev. 2016;29:90-112.

110. Liu X-F, Hao J-L, Xie T, et al. Nrf2 as a target for prevention of age-related and diabetic cataracts by against oxidative stress. Aging Cell. 2017;16: 934-942.

111. Diot A, Morten K, Poulton J. Mitophagy plays a central role in mitochondrial ageing. Mamm Genome. 2016;27:381-395.
112. Hernández-Aguilera H, Fernández-Arroyo $S$, Cuyàs $E$, et al. Epigenetics and nutrition-related epidemics of metabolic diseases: current perspectives and challenges. Food Chem Toxicol. 2016;96: 191-204.

113. Hodes RJ, Sierra F, Austad SN, et al. Disease drivers of aging. Ann NY Acad Sci. 2016;1386:45-68.

114. Peleg S, Feller C, Ladurner AG, et al. The metabolic impact on histone acetylation and transcription in ageing. Trends Biochem Sci. 2016;41: 700-711.

115. Sebastián D, Palacín M, Zorzano A. Mitochondrial dynamics: coupling mitochondrial fitness with healthy aging. Trends Mol Med. 2017;23:201 215.

116. Zhang F, Zhang L, Qi Y, et al. Mitochondrial cAMP signaling. Cell Mol Life Sci. 2016;73:4577-4590.

117. Towers CG, Thorburn A. Therapeutic targeting of autophagy. EBioMedicine. 2016;14:15-23.

118. Boya P. Why autophagy is good for retinal ganglion cells? Nat Eye. 2017; 31:185-190.

119. Lesnefsky EJ, Chen Q, Tandler B, et al. Mitochondrial dysfunction and myocardial ischemia-reperfusion: implications for novel therapies. Annu Rev Pharmacol Toxicol. 2017;57:535-565

120. Ploumi C, Daskalaki I, Tavernarakis N. Mitochondrial biogenesis and clearance: a balancing act. FEBS J. 2017;284:183-195.

121. Matenia D, Mandelkow EM. Emerging modes of PINK1 signaling: another task for MARK2. Front Mol Neurosci. 2014;7:37.

122. Pickrell AM, Youle RJ. The roles of PINK1, Parkin, and mitochondrial fidelity in Parkinson's disease. Neuron. 2015;85:257-273.

123. Laforge $M$, Rodrigues $V$, Silvestre $R$, et al. NF- $\kappa B$ pathway controls mitochondrial dynamics. Cell Death Differ. 2016;23:89-98.

124. Narendra DP. Clinical features of Parkinsonism due to PARKIN and PINK1 mutations, the human phenotype. In: Mitochondrial Mechanisms of Degeneration and Repair in Parkinson's Disease. Buhlman LM, (ed.) Springer International Publishing: Switzerland; Chapter 8 pp.159-182; 2016.

125. Altshuler-Keylin S, Kajimura S. Mitochondrial homeostasis in adipose tissue remodeling. Sci Signal. 2017;10:eaai9248.

126. Georgakopoulos ND, Wells G, Campanella M. The pharmacological regulation of cellular mitophagy. Nat Chem Biol. 2017;13:136-146.

127. Melentijevic I, Toth ML, Arnold ML, et al. C. elegans neurons jettison protein aggregates and mitochondria under neurotoxic stress. Nature. 2017:542:367-371.

128. Nũnez-Figueredo Y, Pardo-Andreu GL, Ramírez-Sánchez J, et al. Antioxidant effects of $\mathrm{JM}-20$ on rat brain mitochondria and synaptosomes: Mitoprotection against $\mathrm{Ca}^{2+}$-induced mitochondrial impairment. Brain Res Bull. 2014;109:68-76.

129. González-Durruthy M, Monserrat JM, Alberici LC, et al. Mitoprotec tive activity of oxidized carbon nanotubes against mitochondrial swelling induced in multiple experimental conditions and predictions with new expected-value perturbation theory. RSC Adv. 2015; 5:103229-103245

130. González-Durruthy M, Castro M, Nunes SM, et al. QSPR/QSAR-based Perturbation Theory approach and mechanistic electrochemical assays on carbon nanotubes with optimal properties against mitochondrial Fenton reaction experimentally induced by $\mathrm{Fe}^{2+}$-overload. Carbon. 2017;115:312-330.

131. Bachurin SO, Bovina EV, Ustyugov AA. Drugs in clinical trials for Alzheimer's disease: the major trends. Med Res Rev. 2017;37:1186-1225.

132. Bading $\mathrm{H}$. Therapeutic targeting of the pathological triad of extrasynaptic NMDA receptor signaling in neurodegenerations. J Exp Med. 2017;214:569-578.

133. Palikaras K, Tavernarakis N. Mitochondrial homeostasis: the interplay between mitophagy and mitochondrial biogenesis. Exp Gerontol. 2014; 56:182-188.

134. Huang Z, Ren S, Jiang Y, et al. PINK1 and Parkin cooperatively protect neurons against constitutively active TRP channel-induced retinal degeneration in Drosophila. Cell Death Dis. 2016;7:e2179.

135. Brennan L, Khoury J, Kantorow M. Parkin elimination of mitochondria is important for maintenance of lens epithelial cell ROS levels and survival upon oxidative stress exposure. BBA Mol Basis Dis. 2017;1863: 21-32.

136. Evans TD, Sergin I, Zhang X, et al. Target acquired: selective autophagy in cardiometabolic disease. Sci Signal. 2017;10:eaag2298. 
137. Simon $\mathrm{H}-\mathrm{U}$, Friis $\mathrm{R}$, Tait SWG, et al. Retrograde signaling from autophagy modulates stress responses. Sci Signal. 2017;10:eaag2791.

138. Ren J, Taegtmeyer H. Too much or not enough of a good thing-the Janus faces of autophagy in cardiac fuel and protein homeostasis. J Mol Cell Cardiol. 2015;84:223-226

139. Esner M, Graifer D, Lleonart ME, et al. Targeting cancer cells through antibiotics-induced mitochondrial dysfunction requires autophagy inhibition. Cancer Lett. 2017;384:60-69.

140. Ravanan P, Srikumar F, Talwar P. Autophagy: the spotlight for cellular stress responses. Life Sci. 2017;188:53-67.

141. Stern M. Evidence that a mitochondrial death spiral underlies antagonistic pleiotropy. Aging Cell. 2017;16:435-443.

142. Stoner MW, Thapa D, Zhang M, et al. $\alpha$-Lipoic acid promotes $\alpha$-tubulin hyperacetylation and blocks the turnover of mitochondria through mitophagy. Biochem J. 2016:473:1821-1830.

143. Lee SY, Oh JS, Rho JH, et al. Retinal pigment epithelial cells undergoing mitotic catastrophe are vulnerable to autophagy inhibition. Nat Cell Death Dis. 2014;5:e1303.

144. Cronan JE. Assembly of lipoic acid on its cognate enzymes: an extraordinary and essential biosynthetic pathway. Microbiol Mol Biol Rev. 2016; 80:429-450.

145. van de Mark K, Chen JS, Steliou K, et al. $\alpha$-Lipoic acid induces p27Kipdependent cell cycle arrest in non-transformed cell lines and apoptosis in tumor cell lines. J Cell Physiol. 2003;194:325-340.

146. Mayr JA, Feichtinger RG, Tort F, et al. Lipoic acid biosynthesis defects. J Inherit Metab Dis. 2014;37:553-563.

147. Stevens MJ, Obrosova I, Cao X, et al. Effects of DL-alpha-lipoic acid on peripheral nerve conduction, blood flow, energy metabolism, and oxidative stress in experimental diabetic neuropathy. Diabetes. 2000;49: 1006-1015.

148. Scangas GA, Bleier BS. Anosmia: differential diagnosis, evaluation, and management. Am J Rhinol Allergy. 2017;31:e3-e7.

149. Tibullo D, Volti GL, Giallongo C, et al. Biochemical and clinical relevance of alpha lipoic acid: antioxidant and anti-inflammatory activity, molecular pathways and therapeutic potential. Inflamm Res. 2017;66:947959.

150. Shirani A, Okuda DT, Stüve O. Therapeutic advances and future prospects in progressive forms of multiple sclerosis. Neurotherapeutics. 2016;13:58-69.

151. Garrett NE, Malcangio M, Dewhurst M, et al. Alpha-lipoic acid corrects neuropeptide deficits in diabetic rats via induction of trophic support. Neurosci Lett. 1997;222:191-194.

152. Hounsom L, Corder R, Patel J, et al. Oxidative stress participates in the breakdown of neuronal phenotype in experimental diabetic neuropathy. Diabetologia. 2001;44:424-428.

153. Coppey LJ, Gellett JS, Davidson EP, et al. Effect of antioxidant treatment of streptozotocin-induced diabetic rats on endoneurial blood flow, motor nerve conduction velocity, and vascular reactivity of epineurial arterioles of the sciatic nerve. Diabetes. 2001;50:1927-1937.

154. Steliou K, Perrine SP, Faller DV. Lactic acid in cancer and mitochondrial disease. Drug Dev Res. 2009;70:499-511.

155. Steliou K. Mitochondria-Targeting Antioxidant Therapeutics. US Patent. 8,741,853; 2014

156. Garner WH, Garner MH. Protein disulfide levels and lens elasticity modulation: applications for presbyopia. Invest Ophthalmol Vis Sci. 2016:57:2851-2863.

157. Sozio $P, D^{\prime}$ Aurizio $E$, lannitelli A, et al. Ibuprofen and lipoic acid diamides as potential codrugs with neuroprotective activity. Arch Pharm Chem Life Sci. 2010;343:133-142.

158. Cacciatore I, Marinelli L, Fornasari E, et al. Novel NSAID-derived drugs for the potential treatment of Alzheimer's disease. Int J Mol Sci. 2016;17: 1035.

159. Rosini M, Simoni E, Bartolini M, et al. Exploiting the lipoic acid structure in the search for novel multitarget ligands against Alzheimer's disease. Eur J Med Chem. 2011;46:5435-5442.

160. Zielonka J, Joseph J, Sikora A, et al. Mitochondria-targeted triphenylphosphonium-based compounds: syntheses, mechanisms of action, and therapeutic and diagnostic applications. Chem Rev. 2017; 117:10043-10120.

161. Connell BJ, Saleh MC, Rajagopal D, et al. UPEI-400, a conjugate of lipoic acid and scopoletin, mediates neuroprotection in a rat model of ischemia/reperfusion. Food Chem Toxicol. 2017;100:175-182.
162. Shi C, Zhou X, Zhang J, et al. $\alpha$-Lipoic acid protects against the cytotoxicity and oxidative stress induced by cadmium in HepG2 cells through regeneration of glutathione by glutathione reductase via Nrf2/ARE signaling pathway. Environ Toxicol Pharmacol. 2016;45:274281.

163. Zee T, Bose N, Zee J, et al. $\alpha$-Lipoic acid treatment prevents cystine urolithiasis in a mouse model of cystinuria. Nat Med. 2017;23:288-290.

164. Cuadrado A. NRF2 in neurodegenerative diseases. Curr Opin Toxicol. 2016;1:46-53.

165. Tabei Y, Murotomi K, Umeno A, et al. Antioxidant properties of 5hydroxy-4-phenyl-butenolide via activation of Nrf2/ARE signaling pathway. Food Chem Toxicol. 2017;107:129-137.

166. Loboda A, Damulewicz M, Pyza E, et al. Role of Nrf2/HO-1 system in development, oxidative stress response and diseases: an evolutionarily conserved mechanism. Cell Mol Life Sci. 2016:73:3221-3247.

167. Tian B, Al-Moujahed A, Bouzika P, et al. Atorvastatin promotes phagocytosis and attenuates pro-inflammatory response in human retinal pigment epithelial cells. Sci Rep. 2017;7:2329.

168. Vavvas DG, Daniels AB, Kapsala Z, et al. Regression of some high-risk features of age-related macular degeneration (AMD) in patients receiving intensive statin treatment. EBioMedicine. 2016;5:198-203.

169. Chen W-J, Wu C, Xu Z, et al. Nrf2 protects photoreceptor cells from photo-oxidative stress induced by blue light. Exp Eye Res. 2017;154:151158.

170. Hasegawa E, Inafuku S, Mulki L, et al. Cytochrome P450 monooxygenase lipid metabolites are significant second messengers in the resolution of choroidal neovascularization. Proc Natl Acad Sci U S A. 2017;114:E7545E7553.

171. Laíns I, Miller JB, Park DH, et al. Structural changes associated with delayed dark adaptation in age-related macular degeneration. Ophthalmology. 2017:124:1340-1352.

172. Fine SL, Berger JW, Maguire MG, et al. Age-related macular degeneration. N Engl J Med. 2000;342:483-492.

173. de Jong PT. Age-related macular degeneration. N Engl J Med. 2006;355: 1474-1485.

174. Jager RD, Mieler WF, Miller JW. Age-related macular degeneration. N Engl J Med. 2008;358:2606-2617.

175. Voloboueva LA, Liu J, Suh JH, et al. (R)- $\alpha$-Lipoic acid protects retina pigment epithelial cells from oxidative damage. Invest Ophthalmol Vis Sci. 2005;46:4302-4310.

176. Biewenga GP, Haenen GRMM, Bast A. The pharmacology of the antioxidant lipoic acid. Gen Pharmacol. 1997;29:315-331.

177. Carlson DA, Smith AR, Fischer SJ, et al. The plasma pharmacokinetics of $\mathrm{R}-(+)$-lipoic acid administered as sodium R-(+)-lipoate to healthy human subjects. Altern Med Rev. 2007;12:343-351.

178. Goraca A, Huk-Kolega H, Piechota A, et al. Lipoic acid-biological activity and therapeutic potential. Pharmacol Rep. 2011;63:849-858.

179. Keith DJ, Butler JA, Bemer B, et al. Age and gender dependent bioavailability of R- and R,S- $\alpha$-lipoic acid: a pilot study. Pharmacol Res. 2012; 66:199-206.

180. Hermann R, Niebch G, Borbe HO, et al. Enantioselective pharmacokinetics and bioavailability of $\alpha$-lipoic acid formulations in healthy volunteers. Eur J Pharm Sci. 1996;4:167-174.

181. Nicolson GL, Settineri R, Ellithorpe RR. Neurodegenerative and fatiguing illnesses, infections and mitochondrial dysfunction: use of natural supplements to improve mitochondrial function. Funct Food Health Dis. 2014:4:23-65.

182. Ziegler D, Low PA, Freeman R, et al. Predictors of improvement and progression of diabetic polyneuropathy following treatment with $\alpha$ lipoic acid for 4 years in the NATHAN 1 trial. J Diabetes Complications. 2016:30:350-356.

183. Mishra M, Lillvis J, Seyoum B, et al. Peripheral blood mitochondrial DNA damage as a potential noninvasive biomarker of diabetic retinopathy. Invest Ophthalmol Vis Sci. 2016;57:4035-4044.

184. Nebbioso M, Federici M, Rusciano D, et al. Oxidative stress in preretinopathic diabetes subjects and antioxidants. Diabetes Technol Ther. 2012;14:257-263.

185. Tao $Y$, Jiang $P$, Wei $Y$, et al. $\alpha$-Lipoic acid treatment improves visionrelated quality of life in patients with dry age-related macular degeneration. Tohoku J Exp Med. 2016;240:209-214.

186. Liu R, Wang Y, Pu M, et al. Effect of alpha lipoic acid on retinal ganglion cell survival in an optic nerve crush model. Mol Vis. 2016;22:1122-1136. 
187. Williams DL. Effect of oral alpha lipoic acid in preventing the genesis of canine diabetic cataract: a preliminary study. Vet Sci. 2017;4:18.

188. Osborne NN, Álvarez CN, del Olmo Aguado S. Targeting mitochondrial dysfunction as in aging and glaucoma. Drug Discov Today. 2014;19: 1613-1622.

189. Apostolova N, Victor VM. Molecular strategies for targeting antioxidants to mitochondria: therapeutic implications. Antioxid Redox Signal. 2015; 22:686-729.

190. Guzman-Villanueva D, Weissig V. Delivery of biologically active molecules to mitochondria. In: Mitochondrial Mechanisms of Degeneration and Repair in Parkinson's Disease. Buhlman LM (ed.) Springer International Publishing; Switzerland; Chapter 13 pp. 255-267; 2016.

191. Romano KA, Martinez-del Campo A, Kasahara K, et al. Metabolic, epigenetic, and transgenerational effects of gut bacterial choline consumption. Cell Host Microbe. 2017;22:279-290.

192. Mindel JS, Mittag TW. Choline acetyltransferase in ocular tissues of rabbits, cats, cattle, and man. Invest Ophthalmol Vis Sci. 1976;15:808814.

193. Fgaier H, Mustafa IHI, Awad AAR, et al. Modeling the interaction between $\beta$-amyloid aggregates and choline acetyltransferase activity and its relation with cholinergic dysfunction through two-enzyme/twocompartment model. Comput Math Methods Med. 2015;2015:923762.

194. Adeva-Andany MM, Calvo-Castro I, Fernández- Fernández C, et al. Significance of L-carnitine for human health. IUBMB Life. 2017;69:578-594.

195. Wolf $\mathrm{G}$. The discovery of a vitamin role for carnitine: the first 50 years. J Nuer. 2006;136:2131-2134.

196. Longo N, Frigeni M, Pasquali M. Carnitine transport and fatty acid oxidation. BBA Mol Cell Res. 2016;1863:2422-2435.

197. Mock DM. Biotin: from nutrition to therapeutics. J Nutr. 2017;147:14871492

198. Sezen O, Ertekin MV, Demircan B, et al. Vitamin E and L-carnitine, separately or in combination, in the prevention of radiation-induced brain and retinal damages. Neurosurg Rev. 2008;31:205-213.

199. Virmani A, Diedenhofen A. The possible mechanisms involved in the protection strategies against radiation-induced cellular damage by carnitines. Int J Clin Med. 2015;6:71-80.

200. Crair MC, Mason CA. Reconnecting eye to brain. J Neurosci. 2016;36: 10707-10722.

201. Jorstad NL, Wilken MS, Grimes WN, et al. Stimulation of functional neuronal regeneration from Müller glia in adult mice. Nature. 2017;548: 103-107.

202. Chen X, Su W, Wan T, et al. Sodium butyrate regulates Th17/Treg cell balance to ameliorate uveitis via the Nrf2/HO-1 pathway. Biochem Pharmacol. 2017;142:111-119.

203. Ahmed SMU, Luo L, Namani A, et al. Nrf2 signaling pathway: pivotal roles in inflammation. BBA Mol Basis Dis. 2017;1863:585-597.

204. Zhao Z, Chen Y, Wang J, et al. Age-related retinopathy in NRF2-deficient mice. PLoS One. 2011;6:e19456.

205. Foresti R, Bucolo C, Platania CMB, et al. Nrf2 activators modulate oxidative stress responses and bioenergetics profiles of human retinal epithelial cells cultured in normal or high glucose conditions. Pharmacol Res. 2015;99:296-307.

206. Lin JB, Tsubota K, Apte RS. A glimpse at the aging eye. Nat Aging Mech of Dis. 2016;2:16003.

207. Deliyanti D, Lee JY, Petratos S, et al. A potent Nrf2 activator, dh404, bolsters antioxidant capacity in glial cells and attenuates ischaemic retinopathy. Clin Sci. 2016;130:1375-1387.

208. Prasad KN. Simultaneous activation of Nrf2 and elevation of dietary and endogenous antioxidant chemicals for cancer prevention in humans. Am Coll Nutr. 2016;35:175-184.

209. Qin S, Hou D-X. Multiple regulations of Keap1/Nrf2 system by dietary phytochemicals. Mol Nutr Food Res. 2016;60:1731-1755.

210. Senger DR, Li D, Jaminet S-C, et al. Activation of the Nrf2 cell defense pathway by ancient foods: disease prevention by important molecules and microbes lost from the modern western diet. PLoS One. 2016;11: e0148042.

211. Dinkova-Kostova AT, Fahey JW, Kostov RV, et al. KEAP1 and Done? Targeting the NRF2 pathway with sulforaphane. Trends Food Sci Technol. 2017;69:257-269.

212. Fahey JW, Wade KL, Wehage SL, et al. Stabilized sulforaphane for clinical use: phytochemical delivery efficiency. Mol Nutr Food Res. 2017;61: 1600766.
213. Kim J, Lee $S$, Choi B-R, et al. Sulforaphane epigenetically enhances neuronal BDNF expression and TrkB signaling pathways. Mol Nutr Food Res. 2017;61:1600194.

214. Negrette-Guzmán M, Huerta-Yepez S, Vega MI, et al. Sulforaphane induces differential modulation of mitochondrial biogenesis and dynamics in normal cells and tumor cells. Food Chem Toxicol. 2017;100: 90-102.

215. Kodukula K, Faller DV, Harpp DN, et al. Gut microbiota \& salivary diagnostics: the mouth is salivating to tell us something. BioRes Open Access. 2017;6:123-132.

216. Kugadas A, Wright $Q$, Geddes-McAlister J, et al. Role of microbiota in strengthening ocular mucosal barrier function through secretory $\lg A$. Invest Ophthalmol Vis Sci. 2017;58:4593-4600.

217. Rowan S, Jiang S, Korem T, et al. Involvement of a gut-retina axis in protection against dietary glycemia-induced age-related macular degeneration. Proc Natl Acad Sci U S A. 2017;112:E4472-E4481.

218. Bandello F, Sacconi $R$, Querques $L$, et al. Recent advances in the management of dry age-related macular degeneration: a review. F1000Research. 2017;6:245.

219. Lee AY, Butt T, Chew E, et al. Cost-effectiveness of age-related macular degeneration study supplements in the UK: combined trial and realworld outcomes data. Br J Ophthalmol. 2017 [Epub ahead of print]; DOI: 10.1136/bjophthalmol-2017-310939

220. Laíns I, Kelly RS, Miller JB, et al. Human plasma metabolomics study across all stages of age-related macular degeneration identifies potential lipid biomarkers. Ophthalmology. 2017 [Epub ahead of print]; DOI: org/10.1016/j.ophtha.2017.08.008.

221. Shin $H$, Price $K$, Albert $L$, et al. Changes in the eye microbiota associated with contact lens wearing. mBio. 2016;7:e00198-16.

222. Reyes NJ, Saban DR. A commencement for eye commensals. Immunity. 2017:47:6-8.

223. St. Leger AJ, Desai JV, Drummond RA, et al. An ocular commensal protects against corneal infection by driving an interleukin-17 response from mucosal $\gamma \delta$ T cells. Immunity. 2017;47:148-158.

224. Zhang $X, M$ VJ, Qu Y, et al. Dry eye management: targeting the ocular surface microenvironment. Int J Mol Sci. 2017;18:1398.

225. Milner MS, Beckman KA, Luchs Jl, et al. Dysfunctional tear syndrome: dry eye disease and associated tear film disorders-new strategies for diagnosis and treatment. Curr Opin Ophthalmol. 2017;28(Suppl 1):3.

226. Andrade AS, Salomon TB, Behling CS, et al. Alpha-lipoic acid restores tear production in an animal model of dry eye. Exp Eye Res. 2014;120: $1-9$.

227. Lu M-C, Ji J-A, Jiang Z-Y, et al. The Keap1-Nrf2-ARE pathway as a potential preventive and therapeutic target: an update. Med Res Rev. 2016; 36:924-963.

228. Bresciani A, Missineo A, Gallo M, et al. Nuclear factor (erythroid-derived 2)-like 2 (NRF2) drug discovery: biochemical toolbox to develop NRF2 activators by reversible binding of Kelch-like ECH-associated protein 1 (KEAP1). Arch Biochem Biophys. 2017;631:31-41.

229. Campolo M, Casili G, Biundo F, et al. The neuroprotective effect of dimethyl fumarate in an MPTP-mouse model of Parkinson's disease: involvement of reactive oxygen species/nuclear factor- $\kappa \mathrm{B} /$ nuclear transcription factor related to NF-E2. Antioxid Redox Signal. 2017;27:453-471.

230. Periyasamy $P$, Shinohara T. Age-related cataracts: role of unfolded protein response, $\mathrm{Ca}^{2+}$ mobilization, epigenetic DNA modifications, and loss of Nrf2/Keap1 dependent cytoprotection. Prog Retin Eye Res. 2017;60:1-19.

231. Vu KT, Hulleman JD. An inducible form of Nrf2 confers enhanced protection against acute oxidative stresses in RPE cells. Exp Eye Res. 2017; 164:31-36.

232. Simoni E, Serafini MM, Caporaso R, et al. Targeting the Nrf2/amyloidbeta liaison in Alzheimer's disease: a rational approach. ACS Chem Neurosci. 2017;8:1618-1627.

233. Satoh T, Stalder R, McKercher SR, et al. Nrf2 and HSF-1 pathway activation via hydroquinone-based proelectrophilic small molecules is regulated by electrochemical oxidation potential. ASN Neuro. 2015;7:1.

234. O'Callaghan J, Cassidy PS, Humphries P. Open-angle glaucoma: therapeutically targeting the extracellular matrix of the conventional outflow pathway. Exp Opin Ther Targets. 2017;21:1037-1050.

235. Flaxman SR, Bourne RRA, Resnikoff S, et al. Global causes of blindness and distance vision impairment 1990-2020: a systematic review and meta-analysis. Lancet Glob Health. 2017;5:e1221-e1234. 
236. Andrés-Guerrero V, Bravo-Osuna I, Pilar Pastoriza P, et al. Novel technologies for the delivery of ocular therapeutics in glaucoma. J Drug Deliv Sci Technol. 2017;42:181-192.

237. Livne-Bar I, Wei J, Liu H-H, et al. Astrocyte-derived lipoxins A4 and B4 promote neuroprotection from acute and chronic injury. J Clin Invest. 2017;127:4403-4414.

238. Jonas JB, Aung T, Bourne RR, et al. Glaucoma. Lancet. 2017;390:20832093.

239. Lefevere E, Toft-Kehler AK, Vohra R. et al. Mitochondrial dysfunction underlying outer retinal diseases. Mitochondrion. 2017;36:66-76.

240. Abd AJ, Kanwar RK, Kanwar JR. Aged macular degeneration: current therapeutics for management and promising new drug candidates. Drug Discov Today. 2017;22:1671-1679.

241. Kim J, Kudisch M, da Silva NRK, et al. Long-term intraocular pressure reduction with intracameral polycaprolactone glaucoma devices that deliver a novel anti-glaucoma agent. J Control Release. 2017;269:45-51.

Cite this article as: Moos WH, Faller DV, Glavas IP, Harpp DN, Irwin MH, Kanara I, Pinkert CA, Powers WR, Steliou K, Vavvas DG, Kodukula K (2017) Epigenetic treatment of neurodegenerative ophthalmic disorders: an eye toward the future, BioResearch Open Access 6:1, 169-181, DOI: 10.1089/biores.2017.0036.

\section{Abbreviations Used}

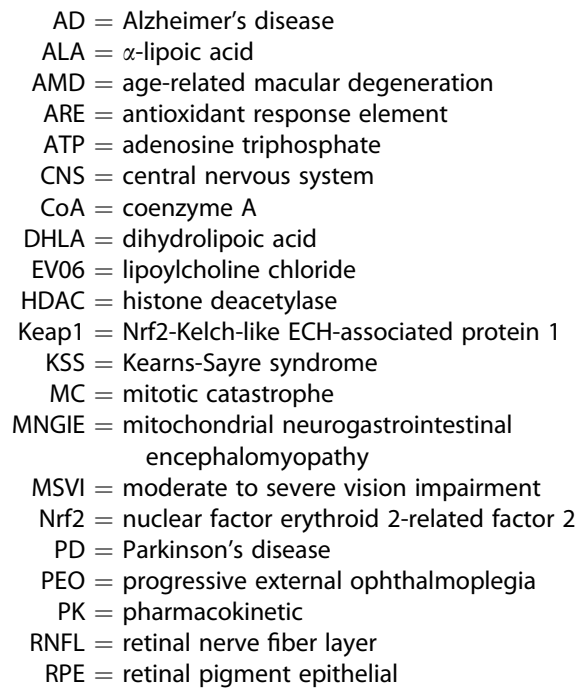

\section{Publish in BioResearch Open Access}

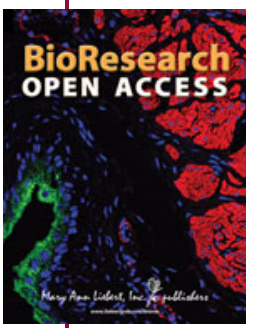

- Broad coverage of biomedical research - Immediate, unrestricted online access - Rigorous peer review - Compliance with open access mandates - Authors retain copyright

- Highly indexed

- Targeted email marketing 